\title{
RUPTURE OF AN ANEURYSM OF THE RIGHT AORTIC SINUS (OF VALSALVA)
}

\author{
BY \\ LEONARD WEISS \\ Formerly of the Department of Pathology, Chase Farm Hospital, Enfield
}

Direct intrapericardial rupture of a congenital aneurysm of the sinus of Valsalva is a rare event. Rupture is said to occur most commonly between the ages of 14 and 30 years (Abbott, 1919). The following case is considered worthy of note, partly on account of the advanced age of the patient.

\section{Case Report}

The patient was a woman aged 72 years. She was said to have been in good health. While having breakfast she suddenly "collapsed". She remained comatose until she died, some 48 hours after the onset of symptoms. The patient came from an Old People's Home, and it was not possible to obtain a more detailed clinical history.

Necropsy Findings. The pericardium was distended with about $200 \mathrm{ml}$. of blood. Within the pericardial sac was a saccular aneurysm of about $8 \mathrm{~cm}$. diameter, which arose from the ascending aorta in the region of the right aortic sinus of Valsalva. The sac competely covered the anterior surface of the right atrium, and was firmly adherent to it. The superior aspect of the sac was adherent to the pericardium. In the ascending aorta were two foramina communicating with the sac; these had smooth rounded edges (Fig. 1) and the superior and inferior foramina were $1 \mathrm{~cm}$. and $2 \mathrm{~cm}$. in diameter, respectively. (The black marker in the photograph goes through the superior foramen, into the aorta.) The sac was $2 \mathrm{~mm}$. thick, and was lined by organizing thrombus, 1 to $2 \mathrm{~mm}$. deep. In the right inferior wall of the sac was a linear tear, $1 \mathrm{~cm}$. long; this was the site of the rupture. The muscle of the right atrium and left ventricle was hypertrophied. The valves, septa, and great vessels were normal. There was no direct channel of communication between the sac and any of the chambers of the heart. There was a moderate degree of pulmonary ôdema. The liver and spleen were congested. The kidneys showed minimal atheromatous change.

Histological sections of the sac show it to be composed mainly of fibrous tissue, with scant amounts of elastic and muscular tissues. Sections of the thoracic and abdominal aortæ show minimal atheromatous change. There was no evidence of syphilitic aortitis or medio-necrosis.

\section{Discussion}

The points of special interest in the case described, are as follows.

First, the advanced age of the patient (72 years). Abbott (1919) gives the average upper age limit as 30 years. The oldest case in Goehring's (1920) series was aged 41 years, and Ostrum et al. (1938) describes one aged 49 years. It would appear that the upper age limit given by Abbott is extremely flexible. Realization of this may help in the diagnosis of the condition during life. This is of increasing importance, as advances in cardiac surgery may soon permit the repair of such aneurysms.

Secondly, the presence of two foramina in the aorta, each communicating with the sac. This suggested that the sac was possibly the end result of a recanalized dissecting aneurysm. Against this, however, is the fact that the rest of the aorta was normal on naked-eye and microscopical examination. Had a dissecting aneurysm occurred, then patches of medio-necrosis or atheromatous plaques would be expected elsewhere in the aorta. A patch or plaque occurring at the site of the aortic sinus, and nowhere else, is extremely unlikely. In the absence of positive pathological findings, the foramina must both be regarded as congenital anomalies. 


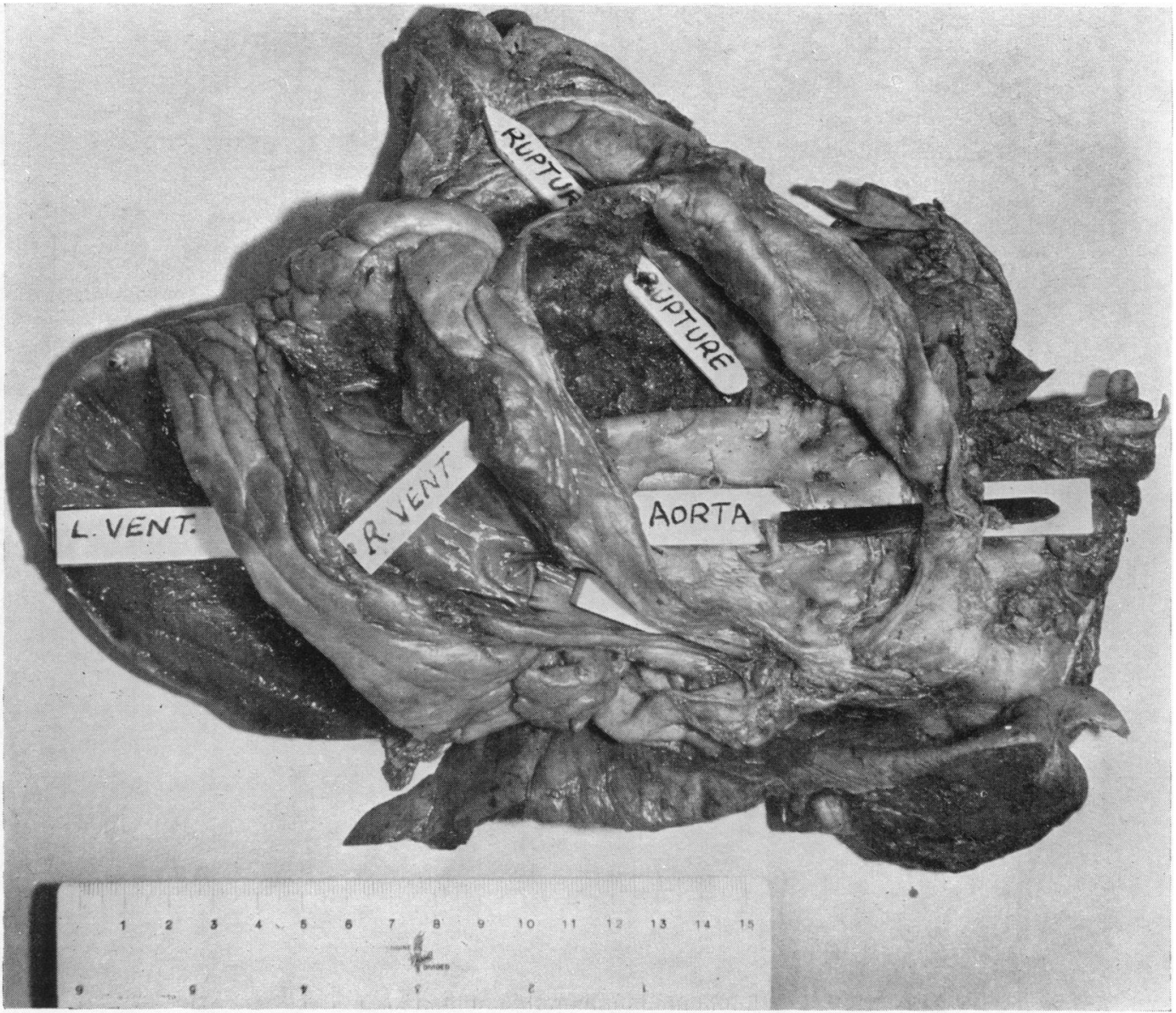

FIG. 1.-Anterior surface of dissected specimen, showing markers going through the site of rupture, and in the aortic foramina.

Thirdly, the long ( 48 hours) interval between rupture of the sac and death, assuming the rupture was heralded by the onset of unconsciousness. Of two cases reported of the rupture of mycotic aneurysms in this region (Ostrum et al., 1938), death was sudden in the first case and due to hæmopericardium. In the second case, the rupture orifice was small, and leakage into the pericardium was slow, with a resulting plastic pericarditis. In the present case, perhaps a factor in retarding the flow of blood into the pericardium was the presence of two aortic orifices. The superior orifice may have acted as a safety valve for the release of pressure within the sac.

Fourthly, intrapericardial rupture is uncommon in these aneurysms. Rupture usually occurs into chambers of vessels in which the blood-pressure is less than in the aorta, resulting in an arteriovenous fistula (Schnitker, 1952).

Fifthly, the absence of an often associated ventricular septal defect. It has been suggested that congenital aneurysms of the right sinus of Valsalva are due to a defect in the fusion of the inferior septum with the aortic septum (Mall, 1912). However, Dilg (1883) found no aneurysms in this region, on examining 61 cases with ventricular septal defects.

\section{Summary}

A description is given of the direct intra-pericardial rupture of a congenital aneurysm of the right sinus of Valsalva, in a patient aged 72 years. 
I wish to thank Dr. J. T. Prendiville for his help and encouragement; Dr. C. J. Gavey and Professor Pulvertaft (Westminster Hospital) for their advice on presenting the case; and Mr. H. Knight for the photograph.

\section{References}

Abbott, M. E. (1919). Sir William Osler Anniversary Volume, 2, 899.

Dilg, J. (1883). Virchow's Archiv., XCI, 193.

Goehring, C. (1920). J. med. Research, XLII, 41-59.

Mall, F. P. (1912). Anat. Rec., 6, 291-298.

Ostrum, H. W., Robinson, B. D., Nichols, C. H., and Widman, B. P. (1938). Amer. J. Roentgen., 40, 828.

Schnitker, M. A. (1952). Congenital Anomalies of the Heart and Great Vessels. P. 256. 